\title{
Validity of Remission Criteria in Rheumatoid Arthritis Compared to Ultrasound-Defined Remission
}

Kawther Ben Abdelghani, Saoussen Miladi, "Yasmine Makhlouf, Alia Fazaa, Mariem Sallemi, Leila Souebni, Kmar Ouenniche, Selma Kassab, Selma Chekili, Kamel Ben Salem, Leith Zakraoui, Ahmed Laatar

\begin{abstract}
Objectives: Remission is the ultimate purpose of treatment in rheumatoid arthritis (RA). However, even when the most stringent composite scores are used, structural damages can occur; hence, ultrasonography (US) appears to be the best way to assess real remission. This study aimed to investigate the validity of different RA remission scores using US as a reference. Methods: An analytic diagnostic study, of 30 RA patients in remission (according to the Disease Activity Score in 28 Joints [DAS28]) and a control group with active RA, was conducted between January and October 2018 at Mongi Slim Hospital in Tunis, Tunisia. Among them, patients in remission were identified according to their Simple Disease Activity Index (SDAI), Clinical Disease Activity Index (CDAI) and the Boolean American College of Rheumatology/European League against Rheumatism activity index (ACR/EULAR) remission scores. The validity of each activity score for remission was calculated by considering the absence of power Doppler (PD) signals as a gold standard. Results: All patients were in remission according to the DAS28, with an average score of 2.03 (1.1-2.6). US examination showed PD signals in 57\% of patients. A total of 26 patients were in remission according to the CDAI; a Doppler signal was detected in $58 \%$ of those cases. SDAI remission was accomplished in 19 patients, with PD activity in $53 \%$ of cases. Of the 14 patients in remission according to the Boolean ACR/EULAR criteria, synovial hyper-vascularisation was found in $64 \%$. Considering true remission as the absence of PD signals, the most sensitive and specific score was the DAS28 (93\% and 68\%, respectively). Conclusion: Considering remission in RA as the absence of vascularised synovitis, the DAS28 is the most sensitive and most specific score.
\end{abstract}

Keywords: Rheumatoid Arthritis; Ultrasonography; Doppler; Reproducibility of Results; Tunisia

\begin{abstract}
AdVANCES IN KNOWLEDGE
Various composite outcome measures exist, but structural damage can occur even when the most stringent ones are used. Using the most reliable composite score is important to achieve low disease activity and remission as a part of a treat-to-target strategy.

Finding the most reliable score using ultrasonography as a reference will facilitate the management of patients with rheumatoid arthritis and would help determine further scores that are more stringent.
\end{abstract}

\section{Application to Patient Care}

Considering true remission as the absence of a power Doppler (PD) signal, it is important to assess the validity of each disease activity score in obtaining remission.

The Disease Activity Score in 28 Joints score seems to be the most valid score for assessing remission when the absence of a PD signal is taken as a reference.

A

CHIEVING REMISSION IS THE ULTIMATE GOAL of treatment in rheumatoid arthritis (RA).

In the past few decades, new therapeutic modalities and strategies have increased the potential to achieve low disease activity and remission by halting the inflammatory process. Indeed, a specific strategy of treating early RA, which is adapted to each patient, includes close follow-ups and aims for less disease activity and lower cost, called 'treat-totarget' and 'treat-to-budget', is now being adopted. ${ }^{1}$ However, the concept of remission is complex, as there is no consensus on its definition. ${ }^{2}$ Based on clinical and biological criteria, several composite scores are available in daily practice; however, structural damage can occur even when the most stringent ones are used. This is because some patients in clinical remission do not experience an absence of disease activity but exhibit a low level of inflammation that is not easily detectable by clinical examination or reflected in laboratory results. The Disease Activity Score in 28 Joints (DAS28) is the most calculated score used in daily practice. This composite score includes objective, subjective and biological data. Other lesser used scores include the simple disease activity index (SDAI), the clinical disease activity index (CDAI) and the Boolean American College of Rheumatology/European League against Rheumatism activity index (ACR/EULAR) remission criteria. All these composite indices differ when considering remission according to their specific cut-offs. Indeed, in the same group of RA patients, the number of those in remission according to the DAS28 was found to be higher compared to other remission 
scores such as the SDAI. ${ }^{3,4}$ Thus, the DAS28 may not be considered the most suitable score to diagnose remission.

Owing to recent technical advances, musculoskeletal ultrasound of the joints now has an important role in the quantification of synovitis. Moreover, it can provide important information for the diagnosis, monitoring and management of RA. The adoption of this tool as an extension to clinical and biological data may be instrumental in the assessment of remission. ${ }^{6}$ Correspondingly, the present study aimed to investigate the validity of different RA disease activity scores to assess remission by using ultrasonography (US) as the reference.

\section{Methods}

This is an analytic, diagnostic monocentric study carried out in the Rheumatology department of Mongi Slim Hospital in Tunis, Tunisia, between January and October 2018. A total of 30 patients with established RA, meeting the criteria of ACR 1987 and in remission according to the EULAR definition (DAS28 score $\leq 2.6$ ), were included. ${ }^{7}$ The inclusion criteria were RA evolving for more than six months, age at the time of diagnosis greater than 16 years and a state of remission (DAS28 $\leq 2.6$ ) diagnosed for at least three months. Patients who had a therapeutic adjustment, flare disease or joint steroid injection in the three months prior to the study date were excluded. A control group (active-RA group) was established to compare the validity of the various criteria for remission. It encompassed 37 patients with active established RA (DAS28 >3.2) .

At inclusion, clinical data including the age of onset of the disease, duration of morning stiffness, number of night awakenings, visual analogic scale (VAS) of pain and patient and physician global assessment (PGA and PhGA) were recorded. A tender and swollen joints count (TJC and SJC) over 66 joints was assessed by the physician who performed the investigation.

Laboratory markers, including C-reactive protein (CRP) and erythrocyte sedimentation rate (ESR) levels, were obtained on the same day. Immunological assessment of the rheumatoid factor (RF), anticitrullinated peptide antibodies (anti-CCPs) and antinuclear antibodies (ANAs) was collected from the recorded data. The functional impact of the disease was assessed using the Health Assessment Questionnaire.

DAS28 is a composite RA activity score of the TJC, SJC, PGA and levels of ESR and CRP. ${ }^{7}$ The
EULAR cut-off for disease activity was used and the study group was found to have a DAS28 score of $\leq 2.6$ and the control group, a DAS28 score of $>3.2$.

Other established scores considered in this study were the SDAI, CDAI and Boolean ACR/EULAR remission criteria. ${ }^{8-10}$ The CDAI includes only clinical parameters: TJC, SJC, PGA and PhGA. The SDAI includes all the aforementioned parameters as well as the CRP levels. The remission cut-offs considered were CDAI $\leq 2.8$, SDAI $\leq 3.3$ or the Boolean ACR/EULAR remission criteria of, for example, TJC $\leq 1, \mathrm{SJC} \leq 1$, CRP $\leq 10 \mathrm{mg} / \mathrm{L}$ and $\mathrm{PGA} \leq 10 .{ }^{11}$

US of the hands and the wrists was performed for each patient with a delay not exceeding 30 minutes after the clinical examination and the biological sampling. The US examination was performed by a rheumatologist with expertise in musculoskeletal US and at least 10 years of field experience. The operator was blinded to the study group and all other study findings. The equipment used was $\mathrm{MyLAb}^{\text {TM }} 60$ (Esaote, Genoa, Italy) with a 6-18 MHz linear array probe. When using power Doppler (PD), the pulse repetition frequency was adjusted at $500-750 \mathrm{~Hz}$ and the receiver gain was adjusted to eliminate the artefact.

Overall, 22 joints were scanned bilaterally per patient, including the wrists, metacarpophalangeal joints (MCP) and proximal interphalangeal joints (PIP). The wrists and MCP were studied on the dorsal side and PIP on their palmar side. The semi-quantitative Szkudlarek scale was used in grey-scale (GS) imaging evaluation for synovial hypertrophy $(\mathrm{SH})$ and in PD. ${ }^{11}$ The sum of grades obtained for each joint and each US mode was established such that it ranged from 0 to 66 for GS and PD.

Ultrasound detection of erosions was not included in this study, as erosions primarily reflect cumulative lesions related to previous history rather than an ongoing inflammation.

To study the validity of the various criteria, the absence of a Doppler signal on the sonogram was considered as the gold standard to define US remission. Sensitivity, specificity and positive and negative predictive values were calculated and compared between the different remission scores using US remission as a reference. Considering US remission, a new threshold for the quantitative scores (DAS28, CDAI, and SDAI) was assessed using a receiver operating characteristic (ROC) curves. Following this, the validity of each score was calculated using the new values. The concordance between the DAS28 and the other RA activity assessment scores (CDAI, SDAI and ACR/EULAR remission) was assessed based on the kappa coefficient using US assessment as a reference. 
The data were transcribed using Excel and analysed using the Statistical Package for the Social Sciences (SPSS), Version 12.0 (IBM Corp., Chicago, Illinois, USA). The simple frequencies and relative frequencies (percentages) of the qualitative variables were calculated. Similarly, the averages and standard deviations were calculated and the extent of the quantitative variables (extreme values: minimum and maximum) was determined. Comparisons of two independent series averages were made using the Mann-Whitney non-parametric test. The independent series percentage comparisons were made using Pearson's Chi-squared test. Comparisons of two percentages on paired series were made using McNemar's test. The links between the two quantitative variables were studied using Spearman's rank correlation coefficient and the differences were found to be significant: $P<0.05$. The agreement between two qualitative variables was measured by Cohen's kappa coefficient. The thresholds for interpreting the kappa coefficient, as determined by Landis and Koch, were as follows: a $\mathrm{K}$ of $0-0.20$ was considered poor, $0.20-0.40$ was fair, $0.40-0.60$ was moderate, $0.60-0.80$ was good and $0.80-1$ was excellent.

Written consent was obtained from the participants. This study was conducted in accordance with the ethical principles of the Declaration of Helsinki and was approved by the Human Research Ethics Committee at Mongi Slim Hospital.

\section{Results}

Overall, 67 patients with RA were included in the study. The participants of the study group $(\mathrm{n}=30)$ were in remission according to the DAS28 for a mean period of 16 months (range: 3-72 months). Half of the patients were under corticosteroids, with an average dosage of $3.75 \mathrm{mg} /$ day (range: $5-10 \mathrm{mg}$ / day). Conventional disease-modifying anti-rheumatic drugs alone were prescribed for $80 \%$ of patients and biotherapies for $20 \%$ of patients. The study group and the control group were comparable for demographic data. In the study group, RF and anti-CCP positivity were found in $60 \%$ and $66 \%$ of patients, respectively. ANAs were available in 23 patients and positive in $10 \%$ of them, with a mean titre of $1 / 160$ (range: $1 / 80-1 / 320$ ). In the active RA group (control group; $\mathrm{n}=37$ ), RF and anti-CCP positivity were observed in $79.8 \%$ and $73.6 \%$ of patients, respectively. ANAs were positive in $6 \%$ of the cases [Table 1 ].

Table 1: Comparison of the demographic and clinical characteristics of 67 patients with rheumatoid arthritis

\begin{tabular}{|c|c|c|c|}
\hline \multirow[t]{2}{*}{ Variable } & \multicolumn{2}{|c|}{ Mean (range) } & \multirow[t]{2}{*}{$P$ value } \\
\hline & $\begin{array}{l}\text { Patients } \\
(\mathbf{n}=30)\end{array}$ & $\begin{array}{c}\text { Controls } \\
(\mathbf{n}=37)\end{array}$ & \\
\hline $\begin{array}{l}\text { Age in years } \\
\pm \mathrm{SD}\end{array}$ & $\begin{array}{c}48 \pm 8.98 \\
(33-67)\end{array}$ & $\begin{array}{l}52.4 \pm 10.3 \\
(30-70)\end{array}$ & 0.38 \\
\hline Gender ratio & 0.20 & 0.15 & 0.5 \\
\hline $\begin{array}{l}\text { Disease } \\
\text { duration in } \\
\text { years } \pm S D\end{array}$ & $\begin{array}{l}8 \pm 4.9 \\
(1-23)\end{array}$ & $\begin{array}{c}10 \\
(0.5-38)\end{array}$ & 0.12 \\
\hline $\begin{array}{l}\text { Night } \\
\text { awakenings }\end{array}$ & $\begin{array}{c}1 \\
(0-1)\end{array}$ & $\begin{array}{l}1.23 \\
(0-4)\end{array}$ & 0.001 \\
\hline $\begin{array}{l}\text { Morning } \\
\text { stiffness in } \\
\text { minutes }\end{array}$ & $\begin{array}{c}2 \\
(0-30)\end{array}$ & $\begin{array}{c}37.7 \\
(0-240)\end{array}$ & 0.001 \\
\hline $\begin{array}{l}\text { Tender joint } \\
\text { count"* }\end{array}$ & $\begin{array}{c}0 \\
(0-1)\end{array}$ & $\begin{array}{c}7 \\
(0-27)\end{array}$ & 0.001 \\
\hline $\begin{array}{l}\text { Swollen joint } \\
\text { count* }\end{array}$ & $\begin{array}{c}0.3 \\
(0-9)\end{array}$ & $\begin{array}{c}6 \\
(0-17)\end{array}$ & 0.001 \\
\hline VAS pain ${ }^{\dagger}$ & $\begin{array}{c}6 \\
(0-10)\end{array}$ & $\begin{array}{c}57 \\
(10-100)\end{array}$ & 0.012 \\
\hline $\mathrm{PGA}^{\dagger}$ & $\begin{array}{c}3 \\
(0-5)\end{array}$ & $\begin{array}{c}5 \\
(20-100)\end{array}$ & 0.025 \\
\hline $\begin{array}{l}\text { ESR in } m m / H \\
\pm S D\end{array}$ & $\begin{array}{l}16.7 \pm 10.4 \\
\quad(2-40)\end{array}$ & $\begin{array}{c}46 \pm 25 \\
(15-110)\end{array}$ & 0.001 \\
\hline $\begin{array}{l}\text { CRP in } \mathrm{mg} / \mathrm{L} \\
\pm \mathrm{SD}\end{array}$ & $\begin{array}{c}3.1 \pm 3.7 \\
(0-19)\end{array}$ & $\begin{array}{c}16.8 \pm 15 \\
(5-59)\end{array}$ & 0.005 \\
\hline $\mathrm{DAS} 28 \pm \mathrm{SD}$ & $\begin{array}{c}2.03 \\
(1.1-2.6)\end{array}$ & $\begin{array}{c}5.2 \\
(3.11-8.6)\end{array}$ & 0.001 \\
\hline HAQ & $\begin{array}{c}0.12 \\
(0-1)\end{array}$ & $\begin{array}{c}1.7 \\
(0-2.62)\end{array}$ & 0.001 \\
\hline
\end{tabular}

$S D=$ standard deviation; $V A S=$ visual analogue scale; $P G A=$ patient global assessment $; E S R=$ erythrocyte sedimentation rate; $C R P=C$-reactive protein; $D A S 28$ = disease activity score 28 joints; $H A Q=$ Health Assessment Questionnaire.

*Can range from $0-28 .{ }^{\dagger}$ Can range from $0-100$
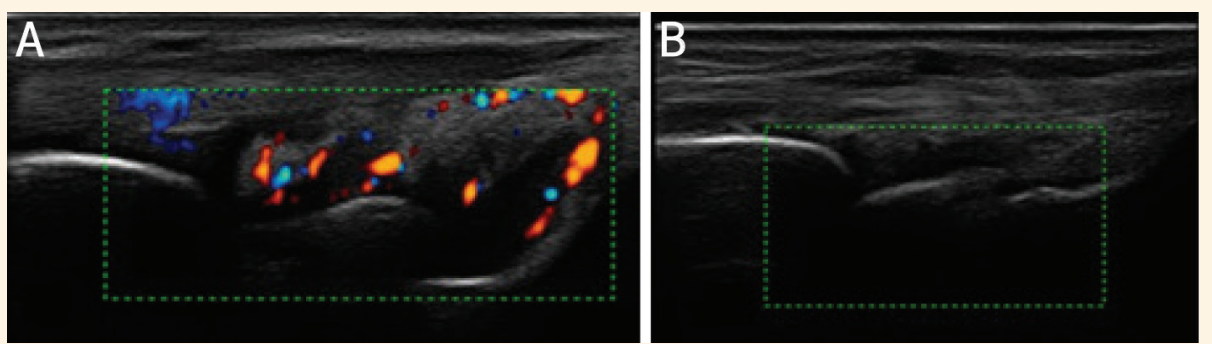

Figure 1: Ultrasound scans of a rheumatoid arthritis patient in clinical remission in power Doppler mode showing (A) a persistent power Doppler image and (B) an image after the power Doppler signal was abolished. 
Table 2: Comparison of the ultrasound grades between the study group and the control group

\begin{tabular}{|c|c|c|c|c|}
\hline \multirow{2}{*}{\multicolumn{2}{|c|}{$\begin{array}{l}\text { Grade } \\
\text { characteristic }\end{array}$}} & \multicolumn{2}{|c|}{ n (\%) } & \multirow{3}{*}{$\begin{array}{c}\boldsymbol{P} \text { value } \\
0.001\end{array}$} \\
\hline & & \multirow{2}{*}{$\begin{array}{l}\text { Study Group } \\
\quad(\mathbf{n}=\mathbf{6 6 0}) \\
571(86)\end{array}$} & \multirow{2}{*}{$\begin{array}{l}\text { Control Group } \\
\qquad(\mathbf{n}=\mathbf{8 1 4}) \\
458(56)\end{array}$} & \\
\hline GS & Grade 0 & & & \\
\hline & Grade 1 & $52(8)$ & 146 (18) & 0.001 \\
\hline & Grade 2 & $31(5)$ & 154 (19) & 0.001 \\
\hline & Grade 3 & $6(1)$ & $56(7)$ & 0.001 \\
\hline \multirow[t]{4}{*}{ PD } & Grade 0 & 616 (93) & $518(64)$ & 0.001 \\
\hline & Grade 1 & $17(3)$ & $9(11)$ & 0.001 \\
\hline & Grade 2 & 17 (3) & $114(14)$ & 0.001 \\
\hline & Grade 3 & $10(0.1)$ & 93 (11) & 0.001 \\
\hline
\end{tabular}

GS $=$ grey scale $P D=$ power Doppler.

Table 3: Reliability of the different scores of remission in the study group

$\begin{array}{lcccc}\begin{array}{l}\text { Remission } \\ \text { score }\end{array} & \text { Sensitivity } & \text { Specificity } & \text { PPV } & \text { NPV } \\ \text { DAS28 } & 93 & 68 & 43 & 97 \\ \text { CDAI } & 92 & 65 & 37 & 97 \\ \text { SDAI } & 90 & 63 & 33 & 97 \\ \text { ACR/EULAR } & 83 & 59 & 17 & 97\end{array}$

PPV = positive predictive value; $N P V=$ negative predictive value; $D A S 28$ = disease activity score 28 joints; $C D A I=$ clinical disease activity index; $S D A I=$ simplified disease activity index; $A C R / E U L A R=$ American College of Rheumatology/European League against Rheumatism.

Table 4: Validity of the different scores of remission after receiver operating characteristic curve thresholds were applied in the study group

\begin{tabular}{lccc|}
$\begin{array}{l}\text { Remission score } \\
\text { threshold }\end{array}$ & \multicolumn{2}{c}{$\%$} & P value \\
$\begin{array}{l}\text { DAS28 threshold } \\
\text { of } 3.2\end{array}$ & 100 & 65.4 & 0.0001 \\
$\begin{array}{l}\text { CDAI threshold } \\
\text { of } 8\end{array}$ & 100 & 79.1 & 0.0001 \\
$\begin{array}{l}\text { SDAI threshold } \\
\text { of } 6.5\end{array}$ & 85.7 & 79.2 & 0.0001 \\
\hline
\end{tabular}

DAS28 = disease activity score 28 joints; $C D A I=$ clinical disease activity index; SDAI = simplified disease activity index.

With regard to the study group, among the 660 joints studied, $\mathrm{SH}$ was detected in $14 \%$ of joints and $\mathrm{PD}$ signals in $7 \%$. The most affected joints were the wrists. When considering the patient scale, synovitis was present in $80 \%$ of patients and PD in $57 \%$ of them [Figure 1].

In the active RA group, among the 814 joints studied using the ultrasonographic scans, $\mathrm{SH}$ was found in $44 \%$ and PD in $36 \%$ of joints; both tended to occur in the wrists. Considering the patient scale, all the patients had $\mathrm{SH}$, with at least one vascularised joint.

When comparing the two groups, a significant difference was noted in both the GS and PD modes. Grade 0 was more frequent in the study group, while grade 3 was more frequent in the active RA (control) group across both modes [Table 2].

The validity of different remission criteria was assessed by considering the absence of any Doppler signals on ultrasonographic scans as the gold standard for defining 'real remission'.

The absence of Doppler signals was found in 13 patients in remission and in one patient in the active RA group. The DAS28 was the most sensitive (93\%) and the most specific (68\%). When considering the state of 'real remission', the thresholds that corresponded to the best sensitivity-specificity couple were 3.2 for the DAS28, 8 for the CDAI and 6.5 for the SDAI. The validity of the different disease activity scores and each score using new limits according to ROC curves are presented in Tables 3 and 4, respectively.

In GS, synovitis was detected in 80\%, 81\%, 79\% and $78 \%$ of patients, using the DAS28, CDAI, SDAI and ACR/EULAR remission criteria, respectively. In the PD mode, vascularised synovitis was present in 57\%, $58 \%, 53 \%$ and $64 \%$ of patients considering the DAS28, CDAI, SDAI and ACR/EULAR remission criteria, respectively. There was no significant correlation between any of the remission criteria used and the US findings either in GS or in PD mode [Table 5].

Among the patients in remission, 26 (87\%) were in remission according to the CDAI, 19 (63\%) were in remission according to the SDAI and 14 (47\%) were in remission according to the ACR/EULAR criteria. The agreement between DAS28 remission and CDAI was excellent $(\kappa=0.88)$, while that between DAS28 and SDAI was good $(\kappa=0.66)$. Furthermore, the agreement between DAS28 and ACR/EULAR remission criteria was moderate $(\kappa=0.47)$.

\section{Discussion}

To the best of the authors' knowledge, this is the first study that investigates the validity of four different clinical remission scores in RA patients using ultrasonographic remission as a gold standard.

In this study, the DAS28 was the most sensitive score (93\%), followed by the CDAI (92\%), SDAI (90\%) and ACR/EULAR remission criteria (83\%). The DAS28 was also the most specific (68\%), followed by the CDAI (65\%), SDAI (63\%) and, finally, ACR/EULAR criteria (59\%). Only one previous study assessed the validity of the SDAI as opposed to that of US in RA patients. 
In that study, Balsa et al. showed that when the cut-off was set to 5 , the sensitivity of SDAI was $65.5 \%$, and the specificity was $55 \% .^{12}$ The specificity of this score was $74.4 \%$ when the cut-off was set to $3.3 .^{12}$ The authors concluded that an SDAI $\leq 3.3$ seemed to be a more specific criterion of true remission that is aimed for by different therapeutic strategies than the DAS28. Indeed, when the DAS28 score was used, a patient could be diagnosed in remission even when they had up to five swollen joints. However, the definition is more stringent with the SDAI, which allows for the presence of either two painful or swollen joints or one painful joint and one swollen joint. ${ }^{13}$

However, based on the present study's results, it was concluded that the DAS28 was more specific than the SDAI and therefore even better suited to assess true remission. The CDAI, which includes only clinical parameters, was found to be more specific than the SDAI for assessing remission. The authors did not find any previous study with similar findings.

Among the multitude of definitions and scores proposed to assess remission, the present study included four, which can be easily used in daily practice. A DAS 28 of $\leq 2.6$ was considered the inclusion criteria, as it is the most used score in daily practice. The concordance between the different RA remission scores compared with the DAS28 was excellent (0.88) for the CDAI, good (0.66) for the SDAI and moderate (0.47) for the ACR/EULAR remission criteria. In a study by Hmamouchi et al., the agreement of the different scores calculated for patients in remission in the French cohort ESPOIR was moderate between the DAS28 and the SDAI remission (0.54) and poor between the DAS28 and the ACR/EULAR remission criteria (0.44). ${ }^{14}$ In another study by Chandrashekara and Priyanka including 100 RA patients in remission, no agreement was found between the DAS28 and ACR/EULAR $(r=-0.16) .{ }^{15}$ However, overall, the present study noted good agreement between the different scores; the differences with other studies could be related to patient selection.

There is no consensus on the number of joints and sites to be assessed by US to evaluate RA activity. Many scores have been proposed for evaluating remission by US. Taking into account the conclusions of various authors, the present study evaluated 22 joints: the wrists, the MCP and the PIP of both hands. In the current study, $80 \%$ of patients had synovitis in GS and 57\% had vascularised ones.

Although heterogeneity was found in published studies, it could be attributed to a different methodology and remission criteria. However, all the studies agreed on the persistence of US activity among patients in remission despite the score used. In a systematic review by Ben Abdelghani et al. comprising 12 studies of RA in remission, synovitis was detected in $50.7-95 \%$ in GS and $14.7-57.4 \%$ in PD. ${ }^{16}$ The detection of synovitis was particularly important, as this infra-clinical activity was responsible for a lownoise evolution during remission. ${ }^{17}$ Importantly, the US scoring system utilized by the current study was the Szkudlarek scale instead of the EULAR as this study was conducted before the validation of the EULAR score. Furthermore, as SH can be seen in many other diseases and even in healthy subjects, the lack of any Doppler signal was considered as the real remission state in the present study.

No correlation between the DAS28 and US score was found in the present study either in the GS or PD mode. Only one previous study assessed the link between the DAS28 and US scores; Balsa et al. observed a positive correlation between DAS28 and PD $(r=0.17 ; P=0.043) .{ }^{12}$ The differences between the study by Balsa et al. and the present study are probably due to the methodologies used. First, the number of patients in remission included in the two studies was different (74 versus 30). Second, inclusion criteria and cut-off values used for assessing remission were different. Finally, these differences could mainly be due to the number of joints evaluated in the US.

The strength of the present study is that it assessed remission scores that are easily used in current practice. Moreover, a control group was included to calculate the validity of the various RA activity scores.

However, the current study also suffered from some limitations. The duration of remission, set to three months at inclusion, may be considered insufficient as the persistence of US synovitis was demonstrated in these patients. In the literature, the minimum duration of remission varied in the range of 3-18 months. ${ }^{18}$ When the duration of remission was prolonged to 12 months, PD was observed in $47.1 \%$ of patients. ${ }^{19}$ Another limitation was that the performance of the US examination depended on the technical characteristics of the device and the operator. In the current study, a single operator performed all the US scanning. It would be interesting to perform the US assessments on two separate occasions and by a second sonologist for better validity of the present results. However, the operator in this study was an expert in US and good intra- and inter-observer reproducibility of the PD had been confirmed by several studies, making its use by a single operator reliable. Another limitation concerns the use of corticosteroids in the remission group; however, the majority of them were treated with low dosages $(<7.5 \mathrm{mg} /$ day) and were in remission for 16 months. 
Finally, the absence of the PD in US was considered a state of 'real remission' in the present study. This choice was based on the results in the literature, which provided evidence that subclinical disease (a persistent PD signal in clinical remission) is predictive of acute flares in RA and even of future structural damage. It is a very stringent criterion; however, this choice could be discussed as a limitation, as, on the one hand, there is no clear consensus on the definition of ultrasound remission and on the other, the implementation of US in everyday practice as well as in follow-ups has been reconsidered in the recent past. Indeed, some authors do not currently support the routine use of US assessment as part of an enhanced treat-to-target strategy recommended by EULAR. ${ }^{20-22}$ According to the results of the Aiming for Remission in rheumatoid arthritis: a randomised trial examining the benefit of ultrasound in a Clinical TIght Control regimen (ARCTIC) trial, the tight control strategy of US did not show additional effect compared to the conventional tight control strategy.22 The results of the Targeting Synovitis in Early Rheumatoid Arthritis (TaSER) study are in line with these findings. ${ }^{23}$ Indeed, aiming for a total PD joint count of $\leq 1$ as part of the ultrasonographic treat-to-target strategy led to more intensive treatment with no better clinical or imaging outcomes when compared to the DAS28-driven strategy (DAS28 <3.2). ${ }^{24}$ Furthermore, raising the level of requirement in treating RA using US as a reference did not augur well for the treat-to-budget concept. More studies are therefore needed to assess the role of US in evaluating disease activity and tailoring treatment in patients with RA. ${ }^{22}$

\section{Conclusion}

The DAS28 and, subsequently, the CDAI seem to be the most specific scores for assessing remission in RA. This is because, compared to other composite scores, they appear to provide the closest possible indicator of the absence of inflammatory activity when considering true remission as the absence of PD signals in US. The findings of the present study could be the basis for further research, which should be conducted with a larger sample to draw effective conclusions.

\section{AUTHORS' CONTRIBUTION}

SM, YM, KO, SK, SC and LZ conceptualised and designed the study. SM and YM collected the data. KA, AF, MS, LS, KO, SK, SC, KS, LZ and AL analysed and interpreted the data. KS performed the statistical analysis. YM performed the literature review and drafted the manuscript. SM edited the manuscript. All authors approved the final version of the manuscript.

\section{CONFLICT OF INTEREST}

The authors declare no conflicts of interest.

\section{FUNDING}

This work received no funding.

\section{References}

1. Sacristán JA, Díaz S, de la Torre I, Inciarte-Mundo J, Balsa A. Treat-to-target and treat-to-budget in rheumatoid arthritis: Measuring the value of individual therapeutic interventions. Rheumatol Ther 2019; 6:473-7. https://doi.org/10.1007/s4074 4-019-00178-3.

2. Paulshus Sundlisæter N, Olsen IC, Aga AB, Hammer HB, Uhlig T, van der Heijde D, et al. Predictors of sustained remission in patients with early rheumatoid arthritis treated according to an aggressive treat-to-target protocol. Rheumatology (Oxford) 2018; 57:2022-31. https://doi.org/10.1093/rheumatology/key202.

3. Khanna D, Oh M, Furst DE, Ranganath V, Gold RH, Sharp JT, et al. Evaluation of the preliminary definitions of minimal disease activity and remission in an early seropositive rheumatoid arthritis cohort. Arthritis Rheum 2007; 57:440-7. https://doi. org/10.1002/art.22619.

4. Smolen JS, Aletaha D. Activity assessments in rheumatoid arthritis. Curr Opin Rheumatol 2008; 20:306-13. https://doi. org/10.1097/BOR.0b013e3282fbd382.

5. Wang X, Qian G, Duan H. Diagnostic value of musculoskeletal ultrasound in rheumatoid finger arthritis. J Coll Physicians Surg Pak 2020; 30:617-21. https://doi.org/10.29271/jcpsp.2020.06.617.

6. Boylan M. Should ultrasound be used routinely in the diagnosis of rheumatoid arthritis? Ir J Med Sci 2020; 189:735-48. https:// doi.org/10.1007/s11845-019-02096-3.

7. Van der Heijde DM, Van't Hof M, Van Riel PL, Van de Putte LB. Development of a disease activity score based on judgment in clinical practice by rheumatologists. J Rheumatol 1993; 20:579-81.

8. Aletaha D, Smolen JS. The simplified disease activity index (SDAI) and clinical disease activity index (CDAI) to monitor patients in standard clinical care. Best Pract Res Clin Rheumatol 2007; 21:663-75. https://doi.org/10.1016/j.berh.2007.02.004.

9. Smolen JS, Breedveld FC, Schiff MH, Kalden JR, Emery P, Eberl G, et al. A simplified disease activity index for rheumatoid arthritis for use in clinical practice. Rheumatology (Oxford) 2003; 42:244-57. https://doi.org/10.1093/rheumatology/keg072.

10. Felson DT, Smolen JS, Wells G, Zhang B, Van Tuyl LH, Funovits J, et al. American College of Rheumatology/European League against Rheumatism provisional definition of remission in rheumatoid arthritis for clinical trials. Ann Rheum Dis 2011; 70:404-13. https://doi.org/10.1136/ard.2011.149765.

11. Felson DT, Smolen JS, Wells G, Zhang B, van Tuyl LH, Funovits J, et al. American College of Rheumatology/European League against Rheumatism provisional definition of remission in rheumatoid arthritis for clinical trials. Ann Rheum Dis 2011; 70:404-13. https://doi.org/10.1136/ard.2011.149765.

12. Balsa A, de Miguel E, Castillo C, Peiteado D, Martin-Mola E. Superiority of SDAI over DAS-28 in assessment of remission in rheumatoid arthritis patients using power Doppler ultrasonography as a gold standard. Rheumatology (Oxford) 2010; 49:683-90. https://doi.org/10.1093/rheumatology/kep442.

13. Smolen JS, Aletaha D. Activity assessments in rheumatoid arthritis. Curr Opin Rheumatol 2008; 20:306-13. https://doi. org/10.1097/BOR.0b013e3282fbd382.

14. Hmamouchi I, Combe B, Fautrel B, Rincheval N, Lukas C. Prevalence and concordance of early and sustained remission assessed by various validated indices in the early arthritis “ESPOIR" cohort. J Bone Spine 2014; 81:409-15. https://doi. org/10.1016/j.jbspin.2014.02.007. 
15. Chandrashekara S, Priyanka B. Remission in rheumatoid arthritis by different criteria does not converge over the inflammatory markers. Int J Rheum Dis 2013; 16:291-6. https://doi.org/10.111 1/1756-185X.12091.

16. Ben Abdelghani K, Miladi S, Souabni L, Kassab S, Chekili S, Laatar A, et al. Role of ultrasound in assessing remission in rheumatoid arthritis. Diagn Interv Imaging 2015; 96:3-10. https://doi.org/10.1016/j.diii.2014.07.006.

17. Vergara F, Ruta S, Rosa J, Marín J, García-Mónaco R, Soriano ER. The value of power Doppler ultrasound in patients with rheumatoid arthritis in clinical remission: Reclassifying disease activity? Reumatol Clin (Engl Ed) 2018; 14:202-6. https://doi. org/10.1016/j.reuma.2017.01.007.

18. Aletaha D, Funovits J, Breedveld FC, Sharp J, Segurado O, Smolen JS. Rheumatoid arthritis joint progression in sustained remission is determined by disease activity levels preceding the period of radiographic assessment. Arthritis Rheum 2009; 60:1242-9. https://doi.org/10.1002/art.24433.

19. Peluso G, Michelutti A, Bosello S, Gremese E, Tolusso B, Ferraccioli G. Clinical and ultrasonographic remission determines different chances of relapse in early and long standing rheumatoid arthritis. Ann Rheum Dis 2011; 70:172-5. https:// doi.org/10.1136/ard.2010.129924.
20. Nessrine A, Siham D, Meryem B, Samira EF, Taoufik H. Should the ultrasound of hands be a component of rheumatoid arthritis remission criteria? Curr Rheumatol Rev 2019; 15:312-5. https://doi.org/10.2174/1573397115666181231115233.

21. Simpson E, Hock E, Stevenson M, Wong R, Dracup N, Wailoo A, et al. What is the added value of ultrasound joint examination for monitoring synovitis in rheumatoid arthritis and can it be used to guide treatment decisions? A systematic review and cost-effectiveness analysis. Health Technol Assess 2018; 22:1-258. https://doi.org/10.3310/hta22200.

22. Smolen JS, Landewé RBM, Bijlsma JWJ, Burmester GR, Dougados M, Kerschbaumer A, et al. EULAR recommendations for the management of rheumatoid arthritis with synthetic and biological disease-modifying antirheumatic drugs: 2019 update. Ann Rheum Dis 2020; 79:685-99. https://doi.org/10.1136/ annrheumdis-2019-216655.

23. Dale J, Stirling A, Zhang R, Purves D, Foley J, Sambrook M, et al. Targeting ultrasound remission in early rheumatoid arthritis: The results of the TaSER study, a randomised clinical trial. Ann Rheum Dis 2016; 75:1043-50. https://doi.org/10.1136/ annrheumdis-2015-208941.

24. Haavardsholm EA, Aga AB, Olsen IC, Lillegraven S, Hammer HB, Uhlig $\mathrm{T}$, et al. Ultrasound in management of rheumatoid arthritis: ARCTIC randomised controlled strategy trial. BMJ 2016; 354:i4205. https://doi.org/10.1136/bmj.i4205. 